\title{
Case report: Severe central nervous system manifestations associated with aberrant efavirenz metabolism in children: the role of CYP2B6 genetic variation
}

Francoise Pinillos ${ }^{1}$, Collet Dandara ${ }^{2}$, Marelize Swart ${ }^{2}$, Renate Strehlau ${ }^{1}$, Louise Kuhn ${ }^{3}$, Faeezah Patel ${ }^{1}$, Ashraf Coovadia ${ }^{1}$ and Elaine Abrams ${ }^{4^{*}}$ (i)

\begin{abstract}
Background: Efavirenz, widely used as part of antiretroviral drug regimens in the treatment of paediatric human immunodeficiency virus infection, has central nervous system side effects. We describe four children presenting with serious, persistent central nervous system adverse events who were found to have elevated plasma efavirenz concentrations as a result of carrying CYP2B6 single nucleotide polymorphisms, known to play a role in the metabolism of EFV. None of the children had a CYP2B6 wildtype haplotype. We believe this is the first case of cerebellar dysfunction associated with efavirenz use to be described in children.

Case presentation: Four black African children, between the ages of 4 and 8 years presenting between 1 and 20 months post-efavirenz initiation, are described. Cerebellar dysfunction, generalised seizures and absence seizures were the range of presenting abnormalities. Plasma efavirenz levels ranged from 20-60 mg/L, 5-15 times the upper limit of the suggested reference range. All abnormal central nervous system manifestations abated after efavirenz discontinuation.

Conclusion: Efavirenz toxicity should always be considered in human immunodeficiency virus-infected children with unexplained central nervous system abnormalities. Our findings further our understanding of the impact of genetic variants on antiretroviral pharmacokinetics in children across various ethnic groups. Screening for potential EFV-toxicity based on the CYP2B6 C.516 SNP alone, may not be adequate.
\end{abstract}

Keywords: Efavirenz, Paediatrics, CYP2B6, HIV, Paediatric HIV, Antiretroviral treatment, CNS, Seizures, Cerebellum

\section{Background}

Efavirenz (EFV) is a potent non-nucleoside reverse transcriptase inhibitor (NNRTI) used as part of combination antiretroviral (ARV) regimens in the treatment of paediatric and adult human immunodeficiency virus (HIV) infection. Central nervous system (CNS) complications associated with EFV use have been well characterised in adults, but are less commonly described in children. We report on four children who presented with serious, persistent CNS adverse effects attributed to EFV toxicity while receiving

\footnotetext{
*Correspondence: eja1@columbia.edu

${ }^{4}$ ICAP, Mailman School of Public Health, and College of Physicians \&

Surgeons Columbia University, 722 W168th street, New York, NY 10032, USA

Full list of author information is available at the end of the article
}

standard recommended weight-based EFV dosing as per South African guidelines. All four children were found to have plasma EFV concentrations above the suggested therapeutic range and carried $C Y P 2 B 6$ single nucleotide polymorphisms (SNPs), CYP2B6 c.516G $>T, C Y P 2 B 6$ c.785A $>G$ and $C Y P 2 B 6$ c.983 $T>C$, which are associated with reduced $C Y P 2 B 6$ function and decreased EFV metabolism Table 1.

\section{Case presentation}

Case-1 [Generalised tonic-clonic seizures]

A 4-year-6-month-old black South African male with perinatal HIV infection presented with generalised tonic- 
Table 1 Case detail summary

\begin{tabular}{|c|c|c|c|c|}
\hline & {$[\text { Case 1] }]^{b}$} & {$[\text { Case } 2]^{b}$} & [Case 3] $]^{\mathrm{ab}}$ & {$\left[\right.$ Case 4] ${ }^{b}$} \\
\hline CNS Adverse Event & $\begin{array}{l}\text { Generalised tonic-clonic } \\
\text { seizures } \\
\text { Aggressive behavior }\end{array}$ & $\begin{array}{l}\text { Acute progressive ataxia, } \\
\text { with cerebellar signs } \\
\text { Anti-social behavior }\end{array}$ & $\begin{array}{l}\text { Generalised tonic-clonic } \\
\text { seizures } \\
\text { Progressively poor school } \\
\text { performance }\end{array}$ & Absence seizures \\
\hline Event Described & $\begin{array}{l}\text { Generalised tonic-clonic } \\
\text { seizure }\end{array}$ & Cerebellar dysfunction & $\begin{array}{l}\text { Generalised tonic-clonic } \\
\text { seizure }\end{array}$ & Absence seizure \\
\hline Sex & Male & Female & Female & Female \\
\hline Starting ART Regimen & $\mathrm{LPV} / \mathrm{r}, 3 \mathrm{TC}, \mathrm{d} 4 \mathrm{~T}$ & $\mathrm{LPV} / \mathrm{r}, 3 \mathrm{TC}, \mathrm{d} 4 \mathrm{~T}$ & $\mathrm{LPV} / \mathrm{r}, 3 \mathrm{TC}, \mathrm{d} 4 \mathrm{~T}$ & RTV, 3TC, d4T \\
\hline Age at ART start (months) & 4.9 & 2.4 & 16.7 & 4 \\
\hline ART regimen at first event & $E F V, 3 T C, A B C$ & $E F V, 3 T C, A B C$ & $E F V, 3 T C, A B C$ & $\mathrm{EFV}, 3 \mathrm{TC}, \mathrm{d} 4 \mathrm{~T}$ \\
\hline $\begin{array}{l}\text { Time on EFV at first event } \\
\text { (months) }\end{array}$ & 3.3 & 19.8 & 13.7 & 0.9 \\
\hline Age at first event & 4 years 6 months & 4 years 10 months & 7 years 6 months & 4 years 7 months \\
\hline $\begin{array}{l}\text { EFV dose at first event } \\
(\mathrm{mg} / \mathrm{kg} / \text { dose) }\end{array}$ & $21 \mathrm{mg} / \mathrm{kg} / \mathrm{dose}$ & $21 \mathrm{mg} / \mathrm{kg} / \mathrm{dose}$ & $15 \mathrm{mg} / \mathrm{kg} / \mathrm{dose}$ & $21 \mathrm{mg} / \mathrm{kg} / \mathrm{dose}$ \\
\hline Age at second event & 5 years & 4 years 11 months & 9 years 5 months & N/A \\
\hline $\begin{array}{l}\text { Time on EFV at second event } \\
\text { (months) }\end{array}$ & 9.6 & 21.3 & 37.9 & N/A \\
\hline $\begin{array}{l}\text { Time on EFV at time of drug } \\
\text { level (months) }\end{array}$ & 10.1 & 23.5 & 49.7 & 1.2 \\
\hline $\begin{array}{l}\text { EFV level mg/L (reference } \\
\text { range) }\end{array}$ & 20 mg/L (1-4 mg/L) & 60.54 mg/L (Ref > 1 mg/L) & 51.23 mg/L (1-4 mg/L) & $19.62 \mathrm{mg} / \mathrm{L}(1-4 \mathrm{mg} / \mathrm{L})$ \\
\hline $\begin{array}{l}\text { Time since last dose prior to } \\
\text { levels (hours) }\end{array}$ & $13 \mathrm{~h}$ post dose & $13 \mathrm{~h}$ post dose & $14 \mathrm{~h}$ post dose & 15 h post dose \\
\hline Genotype & $\begin{array}{l}\text { Heterozygous CYP2B6 516G/T } \\
\text { Heterozygous CYP2B6 } 785 \mathrm{~A} / \mathrm{G}\end{array}$ & $\begin{array}{l}\text { Heterozygous CYP2B6 516G/T } \\
\text { Heterozygous CYP2B6 } 983 \mathrm{~T} / \mathrm{C}\end{array}$ & $\begin{array}{l}\text { Heterozygous CYP2B6 516G/T } \\
\text { Heterozygous CYP2B6 } 983 \mathrm{~T} / \mathrm{C}\end{array}$ & $\begin{array}{l}\text { Homozygous CYP2B6 } \\
516 T / T\end{array}$ \\
\hline
\end{tabular}

${ }^{a}$ Neverest 2 clinical trial (ClinicalTrials.gov, NCT00117728) [3] was a NVP-conserving strategy, aiming to preserve regimens for children exposed to NVP as part of Prevention of Mother-to-Child Transmission (PMTCT). Children were either randomized to continue on a protease inhibitor (PI) or switch to NVP

${ }^{b}$ Neverest 3 clinical trial (ClinicalTrials.gov, NCT01146873) [1] evaluated PI-sparing treatment strategies among NVP-exposed HIV infected children initially treated with lopinavir/ritonavir (LPV/r), but were either randomized to stay on LPV/r or switch to EFV

Abbreviations: LPV/r (lopinavir/ritonavir), 3TC (lamivudine), d4T (stavudine), EFV (efavirenz), RTV (ritonavir), ABC (abacavir), CYP2B6 (Cytochrome P450 2B6), G (guanine), $T$ (thymine), A (adenine), C (cytosine)

clonic seizures, 3 months after initiation of EFV-based antiretroviral treatment (ART).

The child's initial ARV regimen, started at 5 months of age, consisted of lamivudine (3TC), stavudine (d4T), and lopinavir/ritonavir (LPV/r) twice daily (bd). At 4 years of age he was enrolled in a treatment strategy trial evaluating ART switches in virologically suppressed children undertaken at Rahima Moosa Mother and Child Hospital in Johannesburg, South Africa (ClinicalTrials.gov, NCT01146873) [1]. Abacavir (ABC) was substituted for $\mathrm{d} 4 \mathrm{~T}$ and $\mathrm{LPV} / \mathrm{r}$ was switched to EFV 8 weeks thereafter. EFV dosing was prescribed according to standard recommended weight-based dosing as per South African guidelines [2]. Baseline assessment for neuropsychiatric symptoms and neurological examination revealed no abnormalities.

Three months post-EFV initiation, the child was hospitalised for seizures. The mother reported that the child had multiple seizure episodes over a 3-day period with pyrexia. No further information was provided. Lumbar puncture (LP) showed no abnormalities and the child was discharged the following day on an unknown oral antibiotic and paracetamol. After the episode, the mother described the child's behavior as becoming progressively more aggressive; fighting with his siblings; defiant towards his parents, but never violent. Routine clinical examinations revealed no CNS abnormalities.

Ten months after switching to EFV, the child experienced a generalised tonic-clonic seizure while being seen at a routinely scheduled study visit. The seizure lasted for approximately 1 minute, with no urination, tonguebiting, hypersalivation or obvious postictal confusion. The child had been seizure-free and clinically well since his prior hospital admission. In addition to EFV-based ART, tetryzoline (Spersallerg ${ }^{\oplus}$ ) eye drops had been prescribed for allergic conjunctivitis. No known allergies or intolerances were reported.

After the witnessed seizure the child was hospitalised, and investigations including a chest $x$-ray (CXR), urine dipstick, septic blood work-up and LP revealed no abnormalities. The child was discharged the following day with a diagnosis of idiopathic childhood epilepsy and started on 
an antiepileptic drug (AED), sodium valproate, $15 \mathrm{mg} / \mathrm{kg} /$ dose once daily (od). Outpatient electroencephalogram (EEG) revealed no abnormalities and a contrast Computed Tomography brain (CTB) scan showed normal developmental structures, with no lesions or mass effect.

Plasma EFV levels were subsequently measured and genotyping performed as part of clinical care in an attempt to understand the nature of the presenting problem. The plasma EFV level, $13 \mathrm{~h}$ post dose, was $>20.0 \mathrm{mg} / \mathrm{L}$ (suggested reference range: $1-4 \mathrm{mg} / \mathrm{L}$ ) [3] as a result of the genetic characterisation which showed the child to be heterozygous for both CYP2B6 c.516G/T and c.785A/G genotypes. Consequently, EFV was discontinued and LPV/r restarted. The AED was stopped after 7 weeks. No further seizures have been reported, 30 months post-EFV discontinuation, and the aggressive behavior has improved.

\section{Case-2 [Cerebellar dysfunction]}

A 4-year-10-month-old black Zimbabwean female with perinatal HIV infection presented with clinical findings consistent with cerebellar dysfunction, 20 months after being switched to an EFV-based ART regimen.

She was initiated on 3TC, $\mathrm{d} 4 \mathrm{~T}$ and $\mathrm{LPV} / \mathrm{r}$ bd at 10 weeks of age. Achieving and maintaining viral suppression, at 37 months of age she was enrolled in the same clinical trial described above [1] and randomised to substitute $A B C$ for $\mathrm{d} 4 \mathrm{~T}$ and EFV for LPV/r 1 month thereafter. EFV dosing was prescribed according to standard recommended weight-based dosing as per South African guidelines [2]. Baseline assessment for neuropsychiatric symptoms and neurological examination revealed no abnormalities.

Nineteen months after switching to EFV-based ART the child presented with ataxia and tremors. The EFV dose had been increased from $200 \mathrm{mg}$ to $300 \mathrm{mg}$ od 1 week prior to presentation, as part of routine weight-based dose adjustment. At this event, antibiotics were prescribed for a urinary tract infection, and an outpatient CTB scheduled, but was never performed.

Six weeks after the initial presentation the child was noted as having progressively worsening ataxia, marked upper and lower limb tremors and head bobbing. She also complained of epigastric pain and post-prandial vomiting. Examination on hospital admission revealed an ataxic gait, titubation, dysarthria, intention tremor, increased tone with cog-wheel rigidity in all limbs, and truncal hypotonia. Power and reflexes in upper and lower limbs were assessed as normal.

An urgent CTB scan revealed no abnormalities and a follow-up Magnetic Resonance Imaging scan was within normal limits. Laboratory findings including urea, electrolytes, full blood count, C-reactive protein (CRP) all reported within normal limits, and blood culture results showed no bacterial growth. Cerebrospinal fluid analysis was within normal limits. Further investigations, including screening for inborn errors of metabolism, were unable to be carried out as the parents refused further hospital admission.

Follow-up 2 months post-admission showed persistence of the CNS signs and symptoms. At this time, EFV toxicity was considered as a possible cause of the cerebellar dysfunction, drug levels and genotyping were obtained and EFV was replaced with $\mathrm{LPV} / \mathrm{r}$.

Mid-dosing plasma EFV levels, taken $13 \mathrm{~h}$ post dose, were reported at $60.54 \mathrm{mg} / \mathrm{L}$ (suggested reference range: 1-4 mg/L) [3] resulting from CYP2B6 genotyping, where the child was found to be heterozygous carrying both CYP2B6 c.516G/T and c.983 T/C genotypes.

Upon EFV discontinuation, significant improvement of the cerebellar signs and symptoms was noted. Follow up was for a period of 2 months, when the family relocated, 1 month of clinical observation with the caregivers reporting continued clinical improvement telephonically thereafter.

\section{Case-3 [Generalised tonic-clonic seizures]}

A 7-year-6-month-old black South African female with perinatal HIV infection presented with generalised tonic-clonic seizures 14 months after starting an EFV-based regimen.

The child was enrolled in an earlier trial at the same site (ClinicalTrials.gov, NCT00117728) [4] and initiated on 3TC, d4T and LPV/r at 17 months of age. Having achieved viral suppression, she was randomised to substitute NVP for LPV/r 7 months after ART initiation. The diagnosis of pulmonary tuberculosis necessitated discontinuation of NVP and re-introduction of LPV/r at age 3 years 10 months. She was subsequently enrolled in a follow up trial [1] and at age 6 years 4 months, where $\mathrm{LPV} / \mathrm{r}$ was randomised to EFV. EFV dosing was prescribed according to standard recommended weight-based dosing as per South African guidelines [2]. Baseline assessment for neuropsychiatric symptoms and neurological examination revealed no abnormalities.

Thirteen months after starting EFV-based ART, the child was hospitalised with generalised tonic-clonic seizures and a suspected diagnosis of meningoencephalitis and tonsillitis. Neurologically she had a diminished level of consciousness (Glasgow coma scale of 10/15), meningism, increased tone, and brisk reflexes globally. An urgent CTB scan revealed no abnormalities. Besides an elevated CRP, her blood and LP results were within normal limits. On reassessment the following day she was awake, alert and fully cooperative with no meningism, and normal tone and reflexes.

Anti-epileptic therapy, sodium valproate controlled release (CR) tablets $200 \mathrm{mg}$ bd, were started and EFV was continued. She was also discharged on paracetamol and multivitamin. Sodium valproate $\mathrm{CR}$ was stopped when 
the prescription was inadvertently discontinued after 1 month.

The child was admitted 2 years later with her second seizure episode having taken EFV-based ART for a 3year period. Although two further seizure episodes were reported since her prior admission, no medical attention had been sought. Seizures were described by the caregiver as generalised tonic-clonic in nature accompanied by urinary incontinence and a distinct postictal period. On admission the child was apyrexial with a normal physical examination except for enlarged uninfected tonsils. An elevated CRP and white blood cell count were noted, but other investigations were within normal limits. No LP was performed. She was restarted on anticonvulsants, but defaulted treatment after 2 months. An outpatient CTB was found to be normal.

Plasma EFV concentration was measured as a suspected cause of the seizure activity. Plasma EFV level, $14 \mathrm{~h}$ postdose, was $51.23 \mathrm{mg} / \mathrm{L}$ (suggested reference range 1-4 mg/ L) [3] as a result of $C Y P 2 B 6$ genotyping revealing heterozygosity for CYP2B6 c.516G/T and c.983 T/C genotypes. EFV was discontinued and replaced with LPV/r. Followup, 14 months post EFV-discontinuation, has revealed no abnormalities and no further seizures were reported.

\section{Case-4 [Absence seizures]}

As previously described by Strehlau et al., a 4-year-7month-old black South African female presented with new onset absence seizures and behavioral changes 1 month after starting an EFV-based regimen [5].

\section{Conclusions}

For more than a decade, EFV, in combination with a nonnucleoside reverse transcriptase inhibitor backbone, has been recommended as part of the first-line ART regimen for adults and children older than 3 years in South Africa $[2,6-8]$. EFV is an attractive drug for the management of children infected with HIV owing to once-daily dosing, high potency, child-friendly formulations, palatability, and alignment with adult regimens. When compared to NVP in a meta-analysis of adults and children on first-line therapy, EFV was observed to result in fewer treatment discontinuations despite some patients presenting with severe CNS effects [9]. In addition to cutaneous side effects, EFV is most commonly associated with early, mild, transient nervous system side effects in both adults [3, 9-15] as well as children [9, 12, 16]. Dizziness, headaches, nightmares and difficulty sleeping, tend to resolve spontaneously within the first month of treatment. Severe CNS adverse events appear to be infrequent and are not well described in children.

A number of cases of severe adverse CNS side effects associated with EFV use in children have been reported. A 10-year-old girl experienced one episode of generalised seizures 6 weeks after switching from a PI-based to an EFV-based regimen. It was noted that the patient had a strong family history of epilepsy, although she had not previously experienced seizures. ART was not interrupted, she was not initiated on anticonvulsants and the seizures did not recur [17]. Another reported case of a 12-year-old girl presenting with psychosis associated with long term EFV use with genetic analysis showing a heterozygous CYP2B6 c.516G/T genotype [18]. Two of the 33 children (6\%) reported on in an EFV pharmacokinetics study, presented with adverse events, namely a psychotic reaction and seizures, with no further details provided [19].

In this case series, we describe severe CNS adverse events in four children between 4 and 8 years of age presenting between 1 and 20 months post-EFV initiation. In all four cases the plasma EFV levels were substantially higher than the upper limit of the therapeutic range $(1-4 \mathrm{mg} / \mathrm{L})$ [3]. Children in this series presented with a variety of abnormal CNS signs and symptoms - absence seizures, generalised seizures, and cerebellar dysfunction. We believe this is the first case of cerebellar dysfunction associated with EFV treatment to be described in a child. Furthermore, in three of the cases, CNS sequelae manifested late, 3-20 months, after switching to EFV. All four cases showed significant improvement, and even resolution of the CNS abnormalities, once EFV treatment was discontinued.

EFV is primarily metabolised by the CYP2B6 enzyme and to a lesser extent by CYP3A5, CYP3A4, CYP2A6 and CYP1A2 isoforms of the cytochrome P450 system in the liver [20, 21]. The gene coding for CYP2B6 is highly polymorphic and the CYP2B6 c.516G > T SNPs [11, 21-32] and CYP2B6 c.983 $T>C$ SNPs [23, 25, 33-37] have been reportedly associated with reduced EFV oral clearance resulting in increased plasma EFV concentrations. The single nucleotide variant $C Y P 2 B 6$ c.516 $T$ is linked to a CYP2B6 mRNA splice variant that lacks exons four to six and consequently lower levels of functional CYP2B6 enzyme [24], while the CYP2B6 c.983C variant causes a non-synonymous amino acid change from isoleucine to threonine at position 328 in exon 7 and, thus, reduced CYP2B6 activity [37]. Furthermore it is known that significant differences in allele frequencies between different populations exist, for example the frequency of the CYP2B6 c.516 $T$ allele ranges from $14 \%$ in Koreans [38] to $27-30 \%$ in Caucasians [36], $49 \%$ in Africans [39] and $62 \%$ in Papua New Guineans [40]. The CYP2B6 c.983C allele is, however, not observed in Asian or Caucasian individuals, but is present in 4-9\% of Africans and AfricanAmericans [41].

The child in case 4 was homozygous for CYP2B6 c.516 $\mathrm{T} / \mathrm{T}$ which has been shown to be associated with substantially decreased CYP2B6 mRNA expression and therefore higher plasma EFV levels leading to an increased risk of CNS toxicity [3]. In a study done by Swart et al. 
[36], the frequencies of CYP2B6 c.516G/T and T/T genotypes among healthy, black South Africans were 0.48 and 0.13 , respectively. In the same study $88 \%$ of patients with the CYP2B6 c.516 T/T genotype presented with plasma EFV concentrations above the therapeutic range. A significant number of South African HIV-infected patients could potentially benefit from EFV dosage optimisation or reduction.

Both children in cases 2 and 3 carried CYP2B6 c.516G/T and $c .983 \mathrm{~T} / \mathrm{C}$ genotypes, and individuals with dual $c .516 \mathrm{G} /$ $T-c .983 T / C$ heterozygosity are CYP2B6 slow metabolisers, because $C Y P 2 B 6$ c.516 T and CYP2B6 c.983C variants reside on mutually exclusive haplotypes. [42] Carriers of both the CYP2B6 c.516 T and c.983C variants are more likely to present with high plasma EFV levels and exhibit poorer CNS responses [23, 25, 33, 37]. CYP2B6 c.983 T/C and $C / C$ genotypes are present in $5-11 \%$ and $0-2 \%$, respectively, of black South Africans [36]. Swart et al. [36], reported on nine adult patients with both the $c .516 \mathrm{G} / \mathrm{T}$ and c.983 T/C genotypes with an average plasma EFV concentrations $>12 \mathrm{mg} / \mathrm{L}$.

The child described in case 1 was heterozygous for $C Y P 2 B 6$ c.516G $>T$ and the CYP2B6 c.785A $>G$ SNP. Similar to other populations, $C Y P 2 B 6 c .516 G>T$ SNP is in tight linkage disequilibrium with the $c .785 A>G$ SNP. Genotyping for the $c .785 A>G$ SNP, which is located in exon 5 of CYP2B6, is thus not necessary [43, 44]. Studies have reported a gene-dose effect with EFV clearance following the pattern $\mathrm{T} / \mathrm{T}<\mathrm{G} / \mathrm{T}<\mathrm{G} / \mathrm{G}$ and $\mathrm{EFV}$ levels following the pattern $\mathrm{T} / \mathrm{T}>\mathrm{G} / \mathrm{T}>\mathrm{G} / \mathrm{G}[27,29]$. This could explain the lower EFV level in this case, however, genotyping for CYP2B6 c.983 T/C was not performed.

EFV use has been well studied in adult populations, but less so among children where physiological changes may further complicate drug metabolism. For example, hepatic enzyme activity is increased between the ages of 1-4 years, potentially impacting drug metabolism [45]. Findings from Saitoh et al. [27], suggest that age may need to be considered when evaluating the impact of genetic variants on antiretroviral pharmacokinetics in children.

With the increasing use of ART resulting in HIV becoming a chronic disease, and the extended duration perinatally infected children will remain on treatment, reducing long-term ART-related side effects is a priority. A reduced EFV dose of $400 \mathrm{mg}$ from $600 \mathrm{mg}$ in adults was found to be non-inferior with a modest improvement in adverse events [46]. Similarly, an EFV pharmacokinetics study in Ugandan adults suggested that a daily EFV dose of $300 \mathrm{mg}$ may be adequate for individuals carrying the CYP2B6 c.516 T/T genotype [47]. Ter Heine et al. [28], showed that children carrying the CYP2B6 c516G/G genotype had a $50-70 \%$ probability of developing sub-therapeutic EFV concentrations, pointing towards the need for dose optimisation in both adults and children. Cases 1, 2 and 3, as compared to case 4, carried not only the CYP2B6 c. 516G > T SNP but additional heterozygous SNP's conferring impaired CYP2B6 activity resulting in higher plasma EFV concentrations. Thus, screening for potential EFV-toxicity based on the CYP2B6 516 SNP alone would fail to predict the patients with severely impaired EFV metabolism. We hypothesize that genotype-assisted EFV dose optimisation could possibly assist with a reduction in severe CNS toxicities. Both $C Y P 2 B 6$ c.516G $>T$ and c.983 $T>C$ SNP's should be considered in predicting EFV plasma levels pronounced effects, in decreasing the enzyme activity and frequencies of the allelic variants among African populations. While further research characterising the full spectrum of adverse events associated with EFV are needed, clinical vigilance and a high level of suspicion with any reported neurobehavioral or CNS abnormalities for children receiving EFV-based regimens are needed.

\section{Consent}

Genetic characterization was performed as part of the clinical evaluation in each case. Verbal informed consent was obtained from patients' caregivers before testing. Written informed consent was obtained from all patients' caregivers to collate and publish information found in this case report. A copy of the written consent is available for review by the editor of this journal.

\section{Abbreviations \\ 3TC: lamivudine; A: adenine; ABC: abacavir; AED: anti-epileptic drug; ART: antiretroviral therapy; ARV: antiretroviral; bd: twice-daily dosing; C: cytosine; CNS: central nervous system; CR: controlled release; CRP: C-reactive protein; CTB: computed tomography brain; CXR: chest x-ray; CYP2B6: cytochrome P450 2B6; d4T: stavudine; EEG: electroencephalogram; EFV: efavirenz; G: guanine; HIV: human immunodeficiency virus; LP: lumbar puncture; LPV/r: lopinavir/ ritonavir; NNRTI: non-nucleoside reverse transcriptase inhibitor; od: once-daily dosing; SNP: single nucleotide polymorphism; T: thymine.}

\section{Competing interests}

The authors declare that they have no competing interests.

\section{Authors' contributions}

FP was involved in acquisition of data and drafting of final manuscript. $C D$ and MS carried out genotyping analysis and interpretation, drafting of manuscript and critical revision of manuscript for important intellectual content. RS involved in data acquisition, drafting and reviewing of manuscript. LK conceived of the studies participated in and involved in the reviewing of the manuscript. FP involved in data acquisition, drafting and reviewing of manuscript. $A C$ involved in reviewing of the manuscript. EA was involved in drafting of the manuscript, critical revision of the manuscript for important intellectual content and senior overseer. All authors read and approved the final manuscript.

\section{Acknowledgments}

The study was supported by grants (HD061255) from the Eunice Kennedy Shriver National Institutes of Child Health and Human Development (NICHD).

\section{Author details}

${ }^{1}$ Empilweni Services and Research Unit (ESRU), Rahima Moosa Mother and Child Hospital, Department of Paediatrics and Child Health, Faculty of Health Sciences, University of the Witwatersrand, Johannesburg, South Africa.

${ }^{2}$ Pharmacogenetics and Cancer Research Group, Division of Human Genetics, Department of Pathology \& Institute of Infectious Disease and Molecular 
Medicine, University of Cape Town, Cape Town, South Africa. ${ }^{3}$ Gertrude H. Sergievsky Center, College of Physicians and Surgeons; and Department of Epidemiology, Mailman School of Public Health, Columbia University, New York, NY, USA. ${ }^{4}$ ICAP, Mailman School of Public Health, and College of Physicians \& Surgeons Columbia University, 722 W168th street, New York, NY 10032, USA.

Received: 31 October 2015 Accepted: 25 January 2016

Published online: 02 February 2016

\section{References}

1. Coovadia A, Abrams E, Strehlau R, Shiau S, Pinillos F, Martens L, et al. Virologic efficacy of efavirenz maintanance therapy in neviripine prophylaxis-exposed children. Boston: 21st CROl; 2014.

2. National Department of Health. Guidelines for the management of HIV in children. 2nd ed. South Africa: National Department of Health; 2010.

3. Marzolini C, Telenti A, Decosterd LA, Greub G, Biollaz J, Buclin T. Efavirenz plasma levels can predict treatment failure and central nervous system side effects in HIV-1-infected patients. AIDS. 2001;15(1):71-5.

4. Kuhn L, Coovadia A, Strehlau R, Martens L, Hu CC, Meyers T, et al. Switching children previously exposed to nevirapine to nevirapine-based treatment after initial suppression with a protease-inhibitor-based regimen: long-term follow-up of a randomised, open-label trial. Lancet Infect Dis. 2012;12(7):521-30.

5. Strehlau R, Martens L, Coovadia A, Dandara C, Norman J, Maisel J, et al. Absence seizures associated with efavirenz initiation. Pediatr Infect Dis J. 2011;30(11):1001-3.

6. National Department of Health. National antiretroviral treatment guidelines. South Africa: National Department of Health; 2004.

7. National Department of Health. The South African antiretroviral treatment guidelines. South Africa: National Department of Health; 2013.

8. National Department of Health. National consolidated guidelines for the prevention of mother-to-child transmission of HIV (PMTCT) and the management of HIV in children, adolescents and adults. South Africa: National Department of Health; 2015.

9. Shubber Z, Calmy A, Andrieux-Meyer I, Vitoria M, Renaud-Thery F, Shaffer N, et al. Adverse events associated with nevirapine and efavirenz-based firstline antiretroviral therapy: a systematic review and meta-analysis. AIDS. 2013;27(9):1403-12.

10. Clifford DB, Evans S, Yang Y, Acosta EP, Goodkin K, Tashima K, et al. Impact of efavirenz on neuropsychological performance and symptoms in HIVinfected individuals. Ann Intern Med. 2005;143(10):714-21.

11. Clifford DB, Evans S, Yang Y, Acosta EP, Ribaudo H, Gulick RM. Long-term impact of efavirenz on neuropsychological performance and symptoms in HIV-infected individuals (ACTG 5097s). HIV Clin Trials. 2009;10(6):343-55.

12. Ford N, Shubber Z, Pozniak A, Vitoria M, Doherty M, Kirby C, et al. Comparative safety and neuropsychiatric adverse events associated with efavirenz use in first-line antiretroviral therapy: a systematic review and meta-analysis of randomized trials. J Acquir Immune Defic Syndr. 2015:69(4):422-9.

13. Gazzard B, Balkin A, Hill A. Analysis of neuropsychiatric adverse events during clinical trials of efavirenz in antiretroviral-naive patients: a systematic review. AIDS Rev. 2010;12(2):67-75.

14. Kenedi CA, Goforth HW. A systematic review of the psychiatric side-effects of efavirenz. AIDS Behav. 2011;15(8):1803-18.

15. Read TR, Carey D, Mallon P, Mijch A, Goodall R, Hudson F, et al. Efavirenz plasma concentrations did not predict cessation of therapy due to neuropsychiatric symptoms in a large randomized trial. AIDS. 2009;23(16): 2222-3.

16. Teglas JP, Quartier P, Treluyer JM, Burgard M, Gregoire V, Blanche S. Tolerance of efavirenz in children. AIDS. 2001;15(2):241-3.

17. McComsey G, Bhumbra N, Ma JF, Rathore M, Alvarez A. Impact of protease inhibitor substitution with efavirenz in HIV-infected children: results of the first pediatric switch study. Pediatrics. 2003;111(3):e275-81.

18. Lowenhaupt EA, Matson K, Qureishi B, Saitoh A, Pugatch D. Psychosis in a 12-year-old HIV-positive girl with an increased serum concentration of efavirenz. Clin Infect Dis. 2007;45(10):e128-30.

19. Wintergerst U, Hoffmann F, Jansson A, Notheis G, Huss K, Kurowski M, et al. Antiviral efficacy, tolerability and pharmacokinetics of efavirenz in an unselected cohort of HIV-infected children. J Antimicrob Chemother. 2008;61(6):1336-9.
20. di lulio J, Fayet A, Arab-Alameddine M, Rotger M, Lubomirov R, Cavassini M, et al. In vivo analysis of efavirenz metabolism in individuals with impaired CYP2A6 function. Pharmacogenet Genomics. 2009;19(4):300-9.

21. Ward BA, Gorski JC, Jones DR, Hall SD, Flockhart DA, Desta Z. The cytochrome P450 2B6 (CYP2B6) is the main catalyst of efavirenz primary and secondary metabolism: implication for HIV/AIDS therapy and utility of efavirenz as a substrate marker of CYP2B6 catalytic activity. J Pharmacol Exp Ther. 2003;306(1):287-300.

22. Cabrera SE, Santos D, Valverde MP, Dominguez-Gil A, Gonzalez F, Luna G, et al. Influence of the cytochrome P450 2B6 genotype on population pharmacokinetics of efavirenz in human immunodeficiency virus patients. Antimicrob Agents Chemother. 2009;53(7):2791-8.

23. Cortes CP, Siccardi M, Chaikan A, Owen A, Zhang G, la Porte CJ. Correlates of efavirenz exposure in Chilean patients affected with human immunodeficiency virus reveals a novel association with a polymorphism in the constitutive androstane receptor. Ther Drug Monit. 2013;35(1):78-83.

24. Hofmann MH, Blievernicht JK, Klein K, Saussele T, Schaeffeler E, Schwab M, et al. Aberrant splicing caused by single nucleotide polymorphism c.516G > T [Q172H], a marker of CYP2B6*6, is responsible for decreased expression and activity of CYP2B6 in liver. J Pharmacol Exp Ther. 2008;325(1):284-92.

25. Holzinger ER, Grady B, Ritchie MD, Ribaudo HJ, Acosta EP, Morse GD, et al. Genome-wide association study of plasma efavirenz pharmacokinetics in AIDS Clinical Trials Group protocols implicates several CYP2B6 variants. Pharmacogenet Genomics. 2012;22(12):858-67.

26. Nolan D, Phillips E, Mallal S. Efavirenz and CYP2B6 polymorphism: implications for drug toxicity and resistance. Clin Infect Dis. 2006; 42(3):408-10.

27. Saitoh A, Fletcher CV, Brundage R, Alvero C, Fenton T, Hsia K, et al. Efavirenz pharmacokinetics in HIV-1-infected children are associated with CYP2B6G516T polymorphism. J Acquir Immune Defic Syndr. 2007;45(3):280-5.

28. ter Heine R, Scherpbier HJ, Crommentuyn KM, Bekker V, Beijnen JH, Kuijpers TW, et al. A pharmacokinetic and pharmacogenetic study of efavirenz in children: dosing guidelines can result in subtherapeutic concentrations. Antivir Ther. 2008;13(6):779-87.

29. Haas DW, Ribaudo HJ, Kim RB, Tierney C, Wilkinson GR, Gulick RM, et al. Pharmacogenetics of efavirenz and central nervous system side effects: an Adult AIDS Clinical Trials Group study. AIDS. 2004;18(18):2391-400.

30. Lee SS, To KW, Lee MP, Wong NS, Chan DP, Li PC, et al. Sleep quality in efavirenz-treated Chinese HIV patients - comparing between GT and GG genotype of CYP2B6-516 G/T polymorphisms. Int J STD AIDS. 2014;25(3): 193-200.

31. Martin AS, Gomez Al, Garcia-Berrocal B, Figueroa SC, Sanchez MC, Calvo Hernandez MV, et al. Dose reduction of efavirenz: an observational study describing cost-effectiveness, pharmacokinetics and pharmacogenetics. Pharmacogenomics. 2014;15(7):997-1006.

32. Powers V, Ward J, Gompels M. CYP2B6 G516T genotyping in a UK cohort of HIV-positive patients: polymorphism frequency and influence on efavirenz discontinuation. HIV Med. 2009;10(8):520-3.

33. Bienvenu E, Swart M, Dandara C, Ashton M. The role of genetic polymorphisms in cytochrome P450 and effects of tuberculosis co-treatment on the predictive value of CYP2B6 SNPs and on efavirenz plasma levels in adult HIV patients. Antiviral Res. 2014;102:44-53.

34. Mehlotra RK, Bockarie MJ, Zimmerman PA. CYP2B6 983T > C polymorphism is prevalent in West Africa but absent in Papua New Guinea: implications for HIV/AIDS treatment. Br J Clin Pharmacol. 2007;64(3):391-5.

35. Sarfo FS, Zhang Y, Egan D, Tetteh LA, Phillips R, Bedu-Addo G, et al. Pharmacogenetic associations with plasma efavirenz concentrations and clinical correlates in a retrospective cohort of Ghanaian HIV-infected patients. J Antimicrob Chemother. 2014;69(2):491-9.

36. Swart M, Skelton M, Ren Y, Smith P, Takuva S, Dandara C. High predictive value of CYP2B6 SNPs for steady-state plasma efavirenz levels in South African HIV/AIDS patients. Pharmacogenet Genomics. 2013;23(8):415-27.

37. Wyen $\mathrm{C}$, Hendra H, Vogel M, Hoffmann C, Knechten H, Brockmeyer NH, et al. Impact of CYP2B6 983T > C polymorphism on non-nucleoside reverse transcriptase inhibitor plasma concentrations in HIV-infected patients. J Antimicrob Chemother. 2008:61(4):914-8.

38. Cho JY, Lim HS, Chung JY, Yu KS, Kim JR, Shin SG, et al. Haplotype structure and allele frequencies of CYP2B6 in a Korean population. Drug Metab Dispos. 2004;32(12):1341-4.

39. Nyakutira C, Roshammar D, Chigutsa E, Chonzi P, Ashton M, Nhachi C, et al. High prevalence of the CYP2B6 516G- > T(*6) variant and effect on the 
population pharmacokinetics of efavirenz in HIV/AIDS outpatients in Zimbabwe. Eur J Clin Pharmacol. 2008;64(4):357-65.

40. Mehlotra RK, Ziats MN, Bockarie MJ, Zimmerman PA. Prevalence of CYP2B6 alleles in malaria-endemic populations of West Africa and Papua New Guinea. Eur J Clin Pharmacol. 2006;62(4):267-75.

41. Klein K, Lang T, Saussele T, Barbosa-Sicard E, Schunck WH, Eichelbaum M, et al. Genetic variability of CYP2B6 in populations of African and Asian origin: allele frequencies, novel functional variants, and possible implications for anti-HIV therapy with efavirenz. Pharmacogenet Genomics. 2005;15(12):861-73.

42. Haas DW, Kwara A, Richardson DM, Baker P, Papageorgiou I, Acosta EP, et al. Secondary metabolism pathway polymorphisms and plasma efavirenz concentrations in HIV-infected adults with CYP2B6 slow metabolizer genotypes. J Antimicrob Chemother. 2014;69(8):2175-82.

43. Haas DW, Gebretsadik T, Mayo G, Menon UN, Acosta EP, Shintani A, et al. Associations between CYP2B6 polymorphisms and pharmacokinetics after a single dose of nevirapine or efavirenz in African americans. J Infect Dis. 2009;199(6):872-80.

44. Leger P, Dillingham R, Beauharnais CA, Kashuba AD, Rezk NL, Fitzgerald DW et al. CYP2B6 variants and plasma efavirenz concentrations during antiretroviral therapy in Port-au-Prince, Haiti. J Infect Dis. 2009;200(6):955-64.

45. Hoody DW, Fletcher CV. Pharmacology considerations for antiretroviral therapy in human immunodeficiency virus (HIV)-infected children. Semin Pediatr Infect Dis. 2003;14(4):286-94.

46. Puls R, Amin J, Losso M, Phanuphak P, Nwizu C, Orrell C, et al. Efficacy of $400 \mathrm{mg}$ efavirenz versus standard $600 \mathrm{mg}$ dose in HIV-infected, antiretroviral-naive adults (ENCORE1): a randomised, double-blind, placebocontrolled, non-inferiority trial. Lancet. 2014;383(9927):1474-82.

47. Mukonzo JK, Owen JS, Ogwal-Okeng J, Kuteesa RB, Nanzigu S, Sewankambo $\mathrm{N}$, et al. Pharmacogenetic-based efavirenz dose modification: suggestions for an African population and the different CYP2B6 genotypes. PLoS One. 2014;9(1):e86919.

\section{Submit your next manuscript to BioMed Central and we will help you at every step:}

- We accept pre-submission inquiries

- Our selector tool helps you to find the most relevant journal

- We provide round the clock customer support

- Convenient online submission

- Thorough peer review

- Inclusion in PubMed and all major indexing services

- Maximum visibility for your research

Submit your manuscript at www.biomedcentral.com/submit

C Biomed Central 